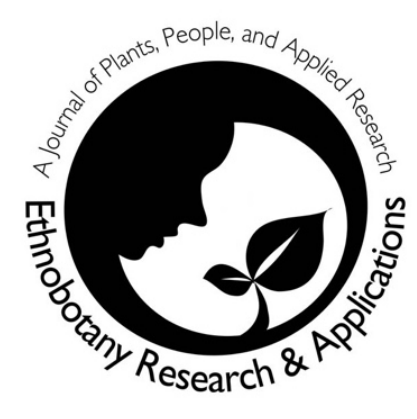

\title{
Entre a tradição e a modernidade: a relação entre as benzedeiras e as plantas medicinais em um centro urbano no sul do Brasil
}

\author{
Camila Fabiana da Silva, Sofia Zank
}

Correspondence

Camila Fabiana da Silva ${ }^{1}$, Sofia Zank ${ }^{2^{*}}$

${ }^{1}$ Centro de Ciências Biológicas, Universidade Federal de Santa Catarina, Florianópolis, Santa Catarina, Brasil. ${ }^{2}$ Laboratório de Ecologia Humana e Etnobotânica, Universidade Federal de Santa Catarina, Florianópolis, Santa Catarina, Brasil. Faculdade Municipal de Palhoça, Palhoça, Santa Catarina, Brasil

*Corresponding Author: sofiazank@gmail.com

Ethnobotany Research and Applications 23:4 (2022)

\section{Repatriation of Etnobotanical Studies}

Repatriated from da Silva, C. F., \& Zank, S. (2022). Between tradition and modernity: the relationship among healers and medicinal plants in an urban center in southern Brazil. Ethnobotany Research and Applications, 23. Retrieved from https://ethnobotanyjournal.org/index.php/era/article/view/2929

\section{Resumo}

Introdução: A benzedura é uma prática tradicional de saúde presente tanto em áreas rurais quanto urbanas do Brasil. Diversos estudos etnobotânicos ressaltam que os praticantes possuem um vasto conhecimento sobre as plantas medicinais, porém ainda é necessário ampliar as investigações sobre a importância da prática e as formas de transmissão dos conhecimentos frente à modernidade. Neste contexto, este estudo foi realizado em uma região urbana de Florianópolis (SC) onde buscamos investigar as doenças tratadas por benzeduras, as plantas utilizadas nesta prática e o processo de transmissão cultural do conhecimento.

Métodos. Realizamos entrevistas com onze benzedeiras da região leste de Florianópolis. A coleta de informações foi realizada através de protocolos semi-estruturados com lista-livre de plantas, e a coleta e identificação botânica das plantas citadas. Os dados foram analisados através de estatística descritiva.

Resultados. Foram levantadas 34 tipos de doenças e males que são tratados através de benzeduras. Para o tratamento e cura desses males foi registrado o uso de 24 espécies de plantas medicinais, sendo as mais citadas: Ruta graveolens (6 citações), Rosmarinus officinalis (3) e Petiveria alliacea (3). Sobre as formas de transmissão do conhecimento, a maioria das entrevistadas (46\%) aprenderam na infância, 36\% na fase adulta através de cursos e $18 \%$ na juventude. Ao longo das entrevistas percebemos que estão surgindo novas formas de transmitir os conhecimentos, onde os cursos e os aplicativos de celulares estão ganhando importância.

Conclusões. A prática da benzedura continua exercendo um papel importante na saúde das comunidades da região leste da Ilha de Santa Catarina e está passando por adaptações frente à modernidade. É importante que estudos futuros investiguem o efeito das tecnologias nesta prática e as possíveis implicações na resiliência ou vulnerabilidade destes sistemas de saúde.

Palavras-chave: Benzedeiras, etnobotânica, práticas de saúde, conhecimento ecológico local, plantas medicinais. 


\section{Introdução}

A benzedura é uma prática tradicional de saúde realizada principalmente por benzedeiras e benzedores que estão presentes tanto nas áreas rurais mais afastadas (Geleski 2014, Zank \& Hanazaki 2016) como também nos centros urbanos (Soares 2001). As benzedeiras e benzedores fazem uso de orações, objetos e plantas medicinais para curar enfermidades físicas ou espirituais (Clarindo et al. 2019, Maciel \& Neto 2006, Sousa et al. 2021, Zank \& Hanazaki 2016) sendo a fé, segundo os praticantes, o fator indispensável para que as benzeduras sejam eficazes (Sousa et al. 2021, Magalhães 2004, Zank \& Hanazaki 2016).

As benzedeiras e benzedores possuem um vasto conhecimento sobre a utilização de plantas medicinais (Amorozo 1999, Ávila 2012, Sousa et al. 2021, Zank \& Hanazaki 2016), que são empregadas em massagens, chás, banhos e remédios caseiros (Oliveira 1985). Além do conhecimento das propriedades medicinais de muitas plantas, os praticantes também acreditam no seu poder espiritual (Dias 2009, Siuda-Ambroziak 2018) e utilizam diversas espécies em suas benzeduras acreditando que juntas exercem maior poder de cura aos pacientes (Fonseca-Kruel \& Peixoto 2004).

A prática da benzedura surgiu da troca de conhecimentos de povos indígenas, africanos e europeus no processo de colonização do Brasil e por muito tempo foi umas das principais formas de atenção básica à saúde da população brasileira (Geleski 2014, Zank \& Hanazaki 2016). A partir da década de 1970, com o processo de modernização e urbanização, e com o avanço da medicina moderna e do acesso facilitado aos seus recursos, a prática da benzedura foi deixando de ter um papel central na atenção à saúde, mas se manteve ao longo do tempo, ocorrendo muitas vezes de forma complementar à medicina moderna (Siuda-Ambroziak 2018, Sousa et al. 2021, Zank \& Hanazaki 2017).

Nas últimas décadas, é possível perceber um processo de valorização dos benzedores e benzedeiras como um reflexo, principalmente, da luta dos povos e comunidades tradicionais brasileiras, que vem garantindo a inclusão deste segmento em políticas públicas de saúde, inclusive na atenção básica de saúde em alguns municípios (Almeida 2012).

Na Ilha de Santa Catarina, no município de Florianópolis (Santa Catarina, Brazil), a benzedura ainda é bastante praticada e possui importância na saúde e na cultura local (Dias 2013, Geleski 2014). Porém, por ser uma capital e com grande desenvolvimento urbano, os efeitos da modernidade vêm influenciando esta prática. Alguns estudos têm demonstrado a percepção de desvalorização e de ameaça à manutenção da prática da benzedura (HoffmanHorochovski 2012, Siuda-Ambroziak 2018). Assim, é importante investigar essa prática no âmbito da etnobotânica a fim de sistematizar o conhecimento e o uso das plantas medicinais e investigar a transmissão cultural do conhecimento, o que ainda não foi realizado na região. Essas informações são essenciais para a compreensão do papel atual da prática da benzedura na saúde das comunidades e na proposição de ações e políticas públicas que valorizem e mantenham essa prática, mesmo diante da modernização.

A transmissão cultural do conhecimento tradicional ocorre principalmente em três formas: vertical - quando a transmissão é entre indivíduos de gerações diferentes, mas dentro da genealogia; horizontal - quando a transmissão é entre membros da mesma geração; e oblíqua - quando a transmissão ocorre entre linhas genealógicas (geração mais velha sem parentesco) (Cavalli-Sforza et al. 1982; Lozada et al. 2006). A transmissão vertical ocorre de "um para poucos" ou "poucos para poucos" e é considerada a forma mais conservadora de transmissão, pois produz taxas moderadas de mudança (Cavalli-Sforza et al. 1982). A transmissão horizontal e oblíqua também pode ocorrer de "um para muitos", como alunos-professores ou líderes sociais, o que pode aumentar a homogeneidade dentro de uma população (Cavalli-Sforza et al. 1982). Estudos sobre o conhecimento das plantas medicinais têm demonstrado que a rota de transmissão do conhecimento das plantas é principalmente vertical (Lozada et al. 2006, Santoro et al., 2020), bem como o conhecimento da prática de benzedura (Zank \& Hanazaki, 2016).

Neste contexto, objetivamos investigar a prática da benzedura na região leste da Ilha de Santa Catarina (Florianópolis, SC, Brazil), com foco no uso de plantas medicinais e nas formas de transmissão cultural dos conhecimentos. A região leste da llha é uma das mais antigas do município, e é conhecida pela facilidade que ainda há em se encontrar benzedores (Dias 2013). Desta forma, neste artigo possuímos como perguntas centrais: a) quais são as doenças tratadas por benzeduras?; b) Quais são as plantas mais importantes e de que forma são utilizadas?; c) Como ocorre o processo de transmissão cultural do conhecimento sobre a prática da benzedura? Por fim, refletimos sobre o efeito da urbanização e modernização na manutenção desta prática tradicional. 


\section{Material e Métodos}

Área de estudo

O estudo foi realizado na ilha de Santa Catarina (entre as coordenadas geográficas $27^{\circ} 22^{\prime}$ e $27^{\circ} 50$ ' latitude sul e $48^{\circ} 25^{\prime}$ e $48^{\circ} 35^{\prime}$ longitude oeste), na cidade de Florianópolis, estado de Santa Catarina, sul do Brasil. Sua área abrange cerca de $675,409 \mathrm{~km}^{2}$ e sua população atual encontra-se em torno de 421.240 habitantes (IBGE 2010). O tipo de clima é Cfa (mesotérmico úmido, com verões quentes e chuvas distribuídas ao longo do ano). A forma de relevo predominante é montanhosa com amplitudes altimétricas superiores a 300 metros e encostas com diferentes graus de inclinação. A ilha tem dois tipos principais de vegetação em diferentes estágios sucessionais: floresta tropical densa e vegetação costeira, que inclui manguezais e restingas (Klein 1978).

A região leste, onde foi realizado este estudo, possui cerca de 23.287 habitantes (IBGE 2010) e abrange os bairros Lagoa da Conceição, Ponta das Almas, Canto dos Araçás, Canto da Lagoa, Costa da Lagoa, Retiro, Joaquina, Fortaleza da Barra da Lagoa, Barra da Lagoa e São João do Rio Vermelho. Nós selecionamos estes bairros para o estudo porque a prática da benzedura ainda faz parte da cultura popular local (Geleski 2014), apesar do processo de modernização da cidade, e é um local supostamente fácil de encontrar benzedeiras e benzedores, visto que são bastante conhecidos pelos moradores das comunidades (Dias 2013).

As comunidades locais possuem fortes características da cultura açoriana, como as rendeiras de bilro, que começaram a surgir no século XVIII com a colonização européia (Silva 2016). Até a década de 1970, a agricultura e a pesca eram as principais atividades econômicas. Porém, com o rápido crescimento da cidade nas últimas décadas, o município passou a ter sua economia baseada principalmente na prestação de serviços públicos, no comércio, na indústria e no turismo (Silva 2016).

\section{Coleta dos dados}

A identificação dos benzedores e benzedeiras presentes em cada um dos bairros da região leste da Ilha de Santa Catarina foi realizada através da metodologia "bola de neve" (Bernard 2005). A identificação inicial começou com um médico do Serviço de Saúde Pública, que já trabalhou nos postos de saúde da região e conhecia benzedeiras locais. Além disso, a cada entrevista os colaboradores eram estimulados a indicar o nome de outros benzedores e benzedeiras da região. A bola de neve foi finalizada quando não houve novas indicações.

Para a coleta de informações foram utilizadas entrevistas semi-estruturadas, com lista-livre de plantas, e a coleta e identificação botânica das plantas citadas. O roteiro de entrevista continha perguntas sobre dados socioeconômicos (nome, gênero, idade, ocupação), os tipos de doenças que são tratadas com as benzeduras (Que tipos de doenças você trata com a benzedura? Nome da doença, descrição e materiais usados), as rezas e plantas utilizadas (Para quais delas usa plantas medicinais? Lista livre com nome da planta e forma de uso), e a forma de transmissão deste conhecimento (Com quem você aprendeu a benzer? Você troca conhecimento sobre orações e plantas com outras/os benzedeiras/os?). A coleta de dados foi realizada no período de 06 de julho de 2018 a 17 de agosto de 2018, e envolveu pelo menos duas visitas a cada um dos entrevistados.

\section{Material botânico}

Através de procedimentos padrões para coletas etnobotânicas (Cunningham 2001) as plantas citadas, quando disponíveis no quintal dos benzedores e benzedeiras, foram coletadas para identificação, montada exsicata de cada uma delas e levadas para o laboratório do Horto Didático de Plantas Medicinais do Hospital Universitário da Universidade Federal de Santa Catarina. As plantas foram identificadas por meio de bibliografias específicas e com o auxílio de especialistas. Pelo fato das plantas citadas neste estudo serem comuns e não estarem férteis, não foi possível depositá-las no herbário da instituição. As plantas foram identificadas com base no material botânico coletado e nas fotografias. A nomenclatura e os nomes das famílias foram verificados no banco de dados Plants of the World Online (http://powo.science.kew.org/) do Royal Botanic Gardens, Kew.

\section{Análise dos dados}

As informações das entrevistas foram tabuladas e analisadas através de estatística descritiva. Foram consideradas apenas as plantas medicinais relacionadas ao tratamento de doenças pela prática de benzeduras. A forma de transmissão do conhecimento foi categorizada de acordo com Cavalli-Sforza et al. (1982) e Lozada et al. (2006) em três categorias: 1) transmissão vertical, quando os participantes relataram ter aprendido com os pais ou avós; 2) transmissão horizontal - quando relataram ter aprendido com pessoas da mesma geração; e 3) transmissão oblíqua - quando relataram ter aprendido com pessoas de outras gerações sem vínculo familiar. Também classificamos a fase da vida em que ocorreu a aprendizagem: A) infância (até 11 anos); B) adolescência (de 12 a 20 anos); C) adulta 
(a partir dos 21 anos). Essa classificação seguiu os documentos nacionais - Estatuto da Criança e do Adolescente (Brasil 1990).

Durante as entrevistas emergiu o aprendizado por meio de cursos, e por mais que os cursos sejam considerados uma forma de transmissão oblíqua, na forma de "um para muitos", optamos por deixá-la em uma categoria separada, já que essa forma de transmissão não é comum no âmbito das benzeduras (Zank \& Hanazaki 2016), e buscamos dar destaque a essa inovação.

\section{Os benzedores do leste da ilha de Santa Catarina}

Identificamos quinze benzedeiras e benzedores na região de estudo e destes onze aceitaram colaborar com a pesquisa. Quatro benzedeiras não aceitaram participar, duas devido a problemas de saúde, uma estava viajando para fora da cidade e uma não quis participar. Das benzedeiras e benzedores entrevistados, a maioria reside no bairro Rio Vermelho (oito), e os demais nos bairros Barra da Lagoa, Lagoa da Conceição e Costa da Lagoa. Como houve apenas um benzedor do gênero masculino identificado, trataremos doravante com o gênero feminino benzedeira.

Ao longo da pesquisa nos deparamos com dois grupos de benzedeiras, que foram classificados como proposto por Gill (2010): 1) Benzedeiras de tradição, que diz respeito às benzedeiras mais antigas e que, em geral, aprenderam as benzeduras através de familiares, amigos e/ou vizinhos, e 2) Benzedeiras de religião, que diz respeito às benzedeiras que aprenderam técnicas de benzeduras em terreiros (espaços de religiões afrobrasileiras).

Cinco benzedeiras foram identificadas como de tradição e seis de religião, sendo que todas de religião residem no bairro Rio Vermelho. As benzedeiras de tradição declararam ser praticantes da religião católica e uma delas declarou, ainda, freqüentar um centro espírita. Por outro lado, todas as benzedeiras de religião declararam serem umbandistas. As benzedeiras dos dois grupos costumam ser devotas de santos do catolicismo, normalmente tendo imagens em suas casas e, algumas delas, possuem utensílios para usos espirituais, como medalhas de santos e crucifixos, demonstrando a existência de um sincretismo religioso associado a esta prática.

No total, dez pessoas entrevistadas são do gênero feminino e uma do gênero masculino, denotando as benzeduras como uma prática realizada comumente, mas não exclusivamente, por mulheres.

A maior parte das benzedeiras possui idade acima dos 60 anos (54,5\%), evidenciando a influência das mulheres mais velhas na prática das benzeduras. As demais benzedeiras possuem idade entre 30 e 59 anos (36,4\%), e embora a prática das benzeduras seja normalmente caracterizada por mulheres mais velhas, foi registrada, também, uma benzedeira com 19 anos de idade.

Em relação à ocupação das benzedeiras, verificou-se que todas as benzedeiras de tradição são aposentadas e isto está relacionado com a idade destas pessoas que possuem mais de 60 anos de idade. As benzedeiras de religião declararam serem estudantes (duas do ensino superior e uma do ensino médio), artesã, massoterapeuta e trabalhadora de serviços gerais.

\section{Resultados}

\section{Doenças tratadas por benzeduras}

Foram levantados 34 tipos de doenças e males que são tratados através de benzeduras, cujas descrições constam na tabela 1. Destas, a maioria (25) estão diretamente relacionadas à problemas físicos do corpo e podem ser associadas a sintomas diagnosticados e tratados também pela medicina moderna, como erisipela, torção ("carnequebrada") e dores em geral (cabeça, rins, barriga, etc). Por outro lado, foram citadas pelo menos nove doenças que estão mais associadas a questões espirituais e energéticas como, por exemplo, quebrante ou mau olhado, susto e embruxado.

Oito benzeduras são praticadas por mais de 2 benzedeiras e 26 foram citadas por apenas uma benzedeira, sendo que neste último caso a maioria é referente a uma benzedeira de religião, que realiza mais de 22 tipos diferentes de benzeduras. Na grande maioria das rezas (19), é utilizada alguma planta para o processo de cura. Além das plantas, também são utilizados outros objetos como pano, agulha, crucifixo, entre outros materiais (Tabela 1). 
Dentre as doenças de origem espiritual ou energética, cabe destacar a denominada como "embruxado", que seria causada por um ataque de bruxa. Esta benzedura foi citada por apenas uma benzedeira de tradição, que é a mais reconhecida localmente. Ela relatou um caso que atendeu uma criança embruxada, a qual foi levada até ela por recomendação de uma médica da região que disse não poder resolver o problema por se tratar de uma doença espiritual. Ao avaliar a criança a benzedeira percebeu que havia mordidas na língua dela causadas por uma bruxa e era por ali que ela sugava a energia da criança. De acordo com a percepção da benzedeira, após rezar algumas vezes a criança foi curada.

Tabela 1. Doenças e males tratados por benzeduras na região leste da ilha de Florianópolis/SC. A descrição das doenças/males foi compilada a partir das explicações das próprias benzedeiras. Trad = Benzedeiras de tradição; Rel $=$ Benzedeiras de religião.

\begin{tabular}{|c|c|c|c|c|c|}
\hline \multirow{2}{*}{ Doenças/males } & \multirow{2}{*}{$\begin{array}{l}\text { Descrição segundo as } \\
\text { benzedeiras }\end{array}$} & \multirow{2}{*}{$\begin{array}{l}\text { Recursos } \\
\text { utilizados }\end{array}$} & \multicolumn{3}{|c|}{$\begin{array}{l}N^{\circ} \text { de bezedeiras/os } \\
(n=11)\end{array}$} \\
\hline & & & Trad & Rel & Total \\
\hline $\begin{array}{l}\text { Quebrante/Mau } \\
\text { olhado }\end{array}$ & $\begin{array}{l}\text { Quando uma pessoa sente inveja } \\
\text { de alguém e deseja ser como ela } \\
\text { ou ter o que ela tem. A vida da } \\
\text { pessoa invejada não prospera. } \\
\text { Ocorre em pessoas e animais. } \\
\text { Sintomas em crianças: tristeza, } \\
\text { falta de apetite, desnutrição. }\end{array}$ & $\begin{array}{l}\text { Planta e } \\
\text { crucifixo }\end{array}$ & 5 & 4 & 9 \\
\hline $\begin{array}{l}\text { Erisipela, Zipra, Zipela } \\
\text { e Zipelão }\end{array}$ & $\begin{array}{l}\text { Problemas nas pernas (do joelho } \\
\text { para baixo) causados por } \\
\text { ferimentos. Sintomas: } \\
\text { vermelhidão, inflamação e dores. }\end{array}$ & $\begin{array}{l}\text { Planta, óleo de } \\
\text { oliva, algodão } \\
\text { ou lã de } \\
\text { carneiro }\end{array}$ & 5 & 2 & 7 \\
\hline $\begin{array}{l}\text { Carne quebrada, } \\
\text { Cosê, Costura, Osso } \\
\text { rendido }\end{array}$ & $\begin{array}{l}\text { Quando ocorre a torção de } \\
\text { alguma parte do corpo, como do } \\
\text { pé ou da mão, que causa } \\
\text { luxação, inchaço, dor muscular } \\
\text { ou inflamação de algum nervo. } \\
\text { Também caracterizado por cortes } \\
\text { e ferimentos. }\end{array}$ & $\begin{array}{l}\text { Pano, agulha e } \\
\text { azeite }\end{array}$ & 2 & 3 & 5 \\
\hline $\begin{array}{l}\text { Espinhela caída e } \\
\text { arca caída }\end{array}$ & $\begin{array}{l}\text { Deslocamento das costelas que } \\
\text { ocorre principalmente em } \\
\text { crianças. Sintomas: dores nas } \\
\text { costas, dores no peito e } \\
\text { dificuldades para respirar. }\end{array}$ & Massagem & 1 & 2 & 3 \\
\hline Susto & $\begin{array}{l}\text { Quando a pessoa leva um susto e } \\
\text { fica "assustada", sendo mais } \\
\text { comum em criança. Sintomas: } \\
\text { dificuldade para dormir e pode } \\
\text { ter diarreias e vômitos. }\end{array}$ & $\begin{array}{l}\text { Sapato } \\
\text { esquerdo da } \\
\text { criança }\end{array}$ & 2 & 1 & 3 \\
\hline Cobreiro & $\begin{array}{l}\text { Alergia específica causada por } \\
\text { bichos que passam pela pele da } \\
\text { pessoa ou por sua roupa. } \\
\text { Sintoma: manchas brancas na } \\
\text { pele que formam pequenas } \\
\text { bolhas de água. }\end{array}$ & $\begin{array}{l}\text { Planta e } \\
\text { corrente de São } \\
\text { Pedro }\end{array}$ & - & 3 & 3 \\
\hline $\begin{array}{l}\text { Sol na cabeça, } \\
\text { Insolação }\end{array}$ & $\begin{array}{l}\text { Dor de cabeça causada por } \\
\text { exposição excessiva ao sol. }\end{array}$ & $\begin{array}{l}\text { Vidro com água } \\
\text { e pano }\end{array}$ & 1 & 1 & 2 \\
\hline Conjuro de roupas & $\begin{array}{l}\text { Problemas em geral como } \\
\text { tristeza, rebeldia, desânimo, } \\
\text { depressão. Reza-se sobre um } \\
\text { objeto pessoal da pessoa, como } \\
\text { foto ou peça de roupa. }\end{array}$ & $\begin{array}{l}\text { Peças de } \\
\text { roupas, fotos }\end{array}$ & - & 2 & 2 \\
\hline
\end{tabular}




\begin{tabular}{|c|c|c|c|c|c|}
\hline Embruxado & $\begin{array}{l}\text { Causada por ataque de bruxas, } \\
\text { principalmente a crianças. } \\
\text { Sintomas: fraqueza, falta de } \\
\text { apetite, insônia. }\end{array}$ & Planta & 1 & - & 1 \\
\hline Amarelão & $\begin{array}{l}\text { Doença causada por vermes que } \\
\text { causa diarreia, dores de barriga e } \\
\text { deixa a pele amarelada. }\end{array}$ & Planta & - & 1 & 1 \\
\hline Bicheira em animais & Ferida com parasitas & - & - & 1 & 1 \\
\hline Bucho virado & Problemas digestivos em crianças & & & 1 & 1 \\
\hline Caxumba & $\begin{array}{l}\text { Doença que surge atrás da } \\
\text { orelha, mais comum em crianças. } \\
\text { Sintomas: inflamação, febre, } \\
\text { dores e falta de apetite. }\end{array}$ & Planta & 1 & - & 1 \\
\hline Constipação & Prisão de ventre & Planta & - & 1 & 1 \\
\hline Cravo & Verrugas que surgem pelo corpo & - & 1 & - & 1 \\
\hline Dor de barriga & $\begin{array}{l}\text { Causada por má digestão ou } \\
\text { gases. }\end{array}$ & Planta & - & 1 & 1 \\
\hline Dor de cabeça, & Em geral & - & - & 1 & 1 \\
\hline Dores localizadas & Em geral & Planta & - & 1 & 1 \\
\hline Febre & $\begin{array}{l}\text { Causada por diversos motivos, } \\
\text { como gripe forte }\end{array}$ & Planta & - & 1 & 1 \\
\hline Ferida brava & Feridas em pessoa com diabete & - & - & 1 & 1 \\
\hline Herpes & $\begin{array}{l}\text { Infecção que afeta os lábios, } \\
\text { Ocorre principalmente em } \\
\text { adultos }\end{array}$ & Planta & - & 1 & 1 \\
\hline Infecção & Em geral & Planta & - & 1 & 1 \\
\hline Inflamação & Em geral & Planta & - & 1 & 1 \\
\hline Mal de 7 dias & $\begin{array}{l}\text { Doença antiga, levava a criança a } \\
\text { morte }\end{array}$ & - & - & 1 & 1 \\
\hline Mal de urina & $\begin{array}{l}\text { Problemas urinários, como } \\
\text { infecções }\end{array}$ & - & - & 1 & 1 \\
\hline Olhos & Conjuntivite & Planta & - & 1 & 1 \\
\hline Parasitas em animais & $\begin{array}{l}\text { Doenças causadas por vermes } \\
\text { que causam desnutrição e } \\
\text { fraqueza em animais }\end{array}$ & Fita vermelha & - & 1 & 1 \\
\hline
\end{tabular}




\begin{tabular}{|c|c|c|c|c|c|}
\hline Reumatismo & Dores no corpo em geral & Planta & 1 & - & 1 \\
\hline Dores nos rins & Dores nos rins & Planta & - & 1 & 1 \\
\hline Abrir caminho & Dissipar problemas diversos & Planta & - & 1 & 1 \\
\hline Auxílio à distância & $\begin{array}{l}\text { Qualquer tipo de problema - } \\
\text { reza feita a distância }\end{array}$ & Planta & - & 1 & 1 \\
\hline $\begin{array}{l}\text { Prosperidade no } \\
\text { comércio }\end{array}$ & $\begin{array}{l}\text { Para pessoa pensar positivo em } \\
\text { relação ao seu negócio }\end{array}$ & - & - & 1 & 1 \\
\hline De chão & Para prosperar a vida & - & - & 1 & 1 \\
\hline Limpeza energética & $\begin{array}{l}\text { Alguns problemas de saúde são } \\
\text { causados por poluição do campo } \\
\text { energético da pessoa. }\end{array}$ & Planta & & 1 & 1 \\
\hline
\end{tabular}

\section{Plantas utilizadas nas benzeduras}

Foram registradas 24 espécies de plantas medicinais utilizadas pelas benzedeiras, com uma média de citação de 3,9 ( $\mathrm{dp}=4,4)$. É importante destacar que as benzedeiras conhecem e usam um número muito superior de plantas medicinais para diferentes tipos de doenças, mas neste estudo focamos apenas nas plantas utilizadas no tratamento de doenças por meio da benzedura.

As plantas mais citadas pelas benzedeiras foram a Ruta graveolens $\mathrm{L}$. (arruda) (6 citações), Rosmarinus officinalis $\mathrm{L}$. (alecrim) (3 citações), Petiveria alliacea L. (guiné) (3 citações), Sansevieria trifasciata Prain (espada-de-São-Jorge) (3 citações), Alternanthera brasiliana (L.) Kuntze (penicilina-vegetal) (3 citações), Solidago chilensis Meyen (arnica) (2 citações), Citrus spp.1 (laranjeira) (2 citações), Bidens pilosa L, (picão-preto) (2 citações), Coriandrum sativum L. (coentro) (2 citações). As demais plantas foram citadas apenas uma vez (Tabela 2).

Table 2. Medicinal plants used in the practice of blessing in the eastern region of the Santa Catarina Island, Florianopolis, SC.

\begin{tabular}{|c|c|c|c|c|c|}
\hline Identificação botânica & $\begin{array}{l}\text { Nome } \\
\text { popular }\end{array}$ & $\begin{array}{l}\text { No. de } \\
\text { citações }\end{array}$ & $\begin{array}{l}\text { doenças/ males } \\
\text { tratados }\end{array}$ & $\begin{array}{l}\text { Forma de } \\
\text { uso }\end{array}$ & $\begin{array}{l}\text { Número de } \\
\text { colecionador ou } \\
\text { identificação } \\
\text { com foto }\end{array}$ \\
\hline \multicolumn{6}{|l|}{ Acanthaceae } \\
\hline Justicia gendarussa Burm. f. & Abre-caminho & 1 & $\begin{array}{l}\text { Abrir caminho } \\
\text { (1) }\end{array}$ & Reza (1) & Foto \\
\hline \multicolumn{6}{|l|}{ Amaranthaceae } \\
\hline $\begin{array}{l}\text { Alternanthera brasiliana (L.) } \\
\text { Kuntze }\end{array}$ & Penicilina & 3 & $\begin{array}{l}\text { Infecções (2), } \\
\text { Erisipela (1) }\end{array}$ & $\begin{array}{l}\text { Chá (2), } \\
\text { reza (1) }\end{array}$ & CS 04 \\
\hline \multicolumn{6}{|l|}{ Anacardiaceae } \\
\hline Mangifera indica $\mathrm{L}$. & Mangueira & 1 & $\begin{array}{l}\text { Limpeza } \\
\text { energética (1) }\end{array}$ & Reza (1) & - \\
\hline \multicolumn{6}{|l|}{ Apiaceae } \\
\hline Coriandrum sativum $\mathrm{L}$. & Coentro & 2 & Inflamação (2) & $\begin{array}{l}\text { Reza (1), } \\
\text { banho (1) }\end{array}$ & Foto \\
\hline Foeniculum vulgare Mill. & Funcho & 1 & Reumatismo (1) & Chá (1) & CS 06 \\
\hline Pimpinella anisum $\mathrm{L}$. & Erva-doce & 1 & Reumatismo (1) & Chá (1) & CS 03 \\
\hline \multicolumn{6}{|l|}{ Aristolochiaceae } \\
\hline $\begin{array}{l}\text { Aristolochia triangularis } \\
\text { Cham }\end{array}$ & $\begin{array}{l}\text { Cipó-mil- } \\
\text { homens }\end{array}$ & 1 & Erisipela (1) & Chá (1) & - \\
\hline \multicolumn{6}{|l|}{ Asteraceae } \\
\hline Bidens pilosa $L$. & Picão-preto & 2 & Amarelão (2) & $\begin{array}{l}\text { Banho (1), } \\
\text { chá (1) }\end{array}$ & CS 02 \\
\hline
\end{tabular}




\begin{tabular}{|c|c|c|c|c|c|}
\hline Solidago chilensis Meyen & Arnica & 2 & $\begin{array}{l}\text { Contusão/ } \\
\text { torção }\end{array}$ & $\begin{array}{l}\text { Reza (1), } \\
\text { banho (1) }\end{array}$ & CS 08 \\
\hline \multicolumn{6}{|l|}{ Boraginaceae } \\
\hline Varronia curassavica Jacq. & Erva-baleeira & 1 & Todas (1) & Reza (1) & CS 01 \\
\hline \multicolumn{6}{|l|}{ Dracaenaceae } \\
\hline Sansevieria trifasciata Prain & $\begin{array}{l}\text { Espada-de- } \\
\text { são-jorge }\end{array}$ & 3 & $\begin{array}{l}\text { Embruxado (2), } \\
\text { Todas (1) }\end{array}$ & $\begin{array}{l}\text { Banho (2), } \\
\text { reza (1) }\end{array}$ & Foto \\
\hline \multicolumn{6}{|l|}{ Geraniaceae } \\
\hline $\begin{array}{l}\text { Pelargonium graveolens } \\
\text { L'Hér }\end{array}$ & $\begin{array}{l}\text { Malva- } \\
\text { cheirosa }\end{array}$ & 1 & Todas (1) & Reza (1) & CS 09 \\
\hline \multicolumn{6}{|l|}{ Lamiaceae } \\
\hline Lavandula sp. & Alfazema & 1 & Embruxado (1) & Banho (1) & Foto \\
\hline $\begin{array}{l}\text { Leonotis nepetifolia (L.) } \\
\text { R.Br. }\end{array}$ & $\begin{array}{l}\text { Cordão-de- } \\
\text { são-francisco }\end{array}$ & 1 & Embruxado (1) & Banho (1) & - \\
\hline Menthasp. & Hortelã & 1 & $\begin{array}{l}\text { Dor de barriga } \\
\text { (1) }\end{array}$ & Chá (1) & Foto \\
\hline Rosmarinus officinalis $L$. & Alecrim & 3 & $\begin{array}{l}\text { Embruxado (1), } \\
\text { calmante (1), } \\
\text { todas (1) }\end{array}$ & $\begin{array}{l}\text { Reza (2), } \\
\text { banho (1) }\end{array}$ & Foto \\
\hline Ocimum americanum $\mathrm{L}$. & Manjericão & 1 & Todas (1) & Reza (1) & Foto \\
\hline \multicolumn{6}{|l|}{ Malvaceae } \\
\hline Sida sp. & Guanxuma & 1 & Caxumba (1) & Reza (1) & - \\
\hline \multicolumn{6}{|l|}{ Myrtaceae } \\
\hline Eugenia uniflora L. & Pitanga & 1 & Erisipelas (1) & Banho (1) & Foto \\
\hline \multicolumn{6}{|l|}{ Phytolaccaceae } \\
\hline Petiveria alliacea $L$. & Guiné & 3 & $\begin{array}{l}\text { Quebrante (2), } \\
\text { embruxado (1) }\end{array}$ & $\begin{array}{l}\text { Reza (2), } \\
\text { banho (1) }\end{array}$ & Foto \\
\hline \multicolumn{6}{|l|}{ Rosaceae } \\
\hline Rosa alba L. & Rosa & 1 & Quebrante (1) & Reza (1) & Foto \\
\hline \multicolumn{6}{|l|}{ Rutaceae } \\
\hline Citrus spp.1 & Laranjeira & 2 & $\begin{array}{l}\text { Erisipelas (1), } \\
\text { todas (1) }\end{array}$ & $\begin{array}{l}\text { Banho (1), } \\
\text { reza (1) }\end{array}$ & CS 07 \\
\hline Citrus spp.2 & Limão & 1 & Herpes (1) & Reza (1) & CS 05 \\
\hline Ruta graveolens L. & Arruda & 6 & $\begin{array}{l}\text { Quebrante (2), } \\
\text { cobreiro (1), } \\
\text { embruxado (1), } \\
\text { todas (2) }\end{array}$ & $\begin{array}{l}\text { Reza (5), } \\
\text { banho (1) }\end{array}$ & Foto \\
\hline
\end{tabular}

Das citações de uso, 53,5\% é referente ao uso durante a reza, 27,9\% para banhos e 18,6\% para chás. As benzedeiras acreditam que as plantas possuem o poder de desfazer problemas espirituais e físicos e por isso as utilizam para realizar as rezas das benzeduras. A escolha das plantas depende do nível do problema e, também, da afinidade entre o benzedor e determinadas ervas (p.ex. as benzedeiras que preferem utilizar uma planta específica para benzer).

\section{Transmissão dos conhecimentos}

Sobre a forma como as benzedeiras aprenderam a benzer, $46 \%$ das entrevistadas disse ter aprendido na infância. Destas, $80 \%$ começaram a benzer somente depois dos 40 anos de idade, após o falecimento de suas mães. Outros $18 \%$ aprenderam na adolescência e $36 \%$ aprenderam na fase adulta.

Das benzedeiras que aprenderam as rezas na infância, todas foram através da transmissão vertical (Figura 1) ao escutarem suas mães e avós rezando nas pessoas que as procuravam. Das benzedeiras que aprenderam na adolescência, as duas aprenderam por transmissão oblíqua, uma observando benzedeiras da comunidade que a benziam, e outra benzedeira relatou ter aprendido em um curso ("um para muitos").

Benzedeiras que aprenderam na idade adulta foram por meio de um curso (oblíquo), que é ministrado por um das benzedeiras que entrevistamos. Ela é responsável por ministrar cursos de treinamento para benzedeiras em um centro religioso afro-brasileiro.

Ao mesmo tempo, todas as benzedeiras disseram que para benzer é necessário que a pessoa tenha o dom, e que para começar a praticar as benzeduras tem que ocorrer um "despertar", ou seja, a pessoa tem que perceber que tem o dom de benzer. Esse despertar em algumas situações está relacionado a experiências espirituais, como visões 
e sonhos. Segundo elas, em algum momento da vida irá acontecer esse despertar e não existe, necessariamente, uma idade ideal para que isso aconteça.

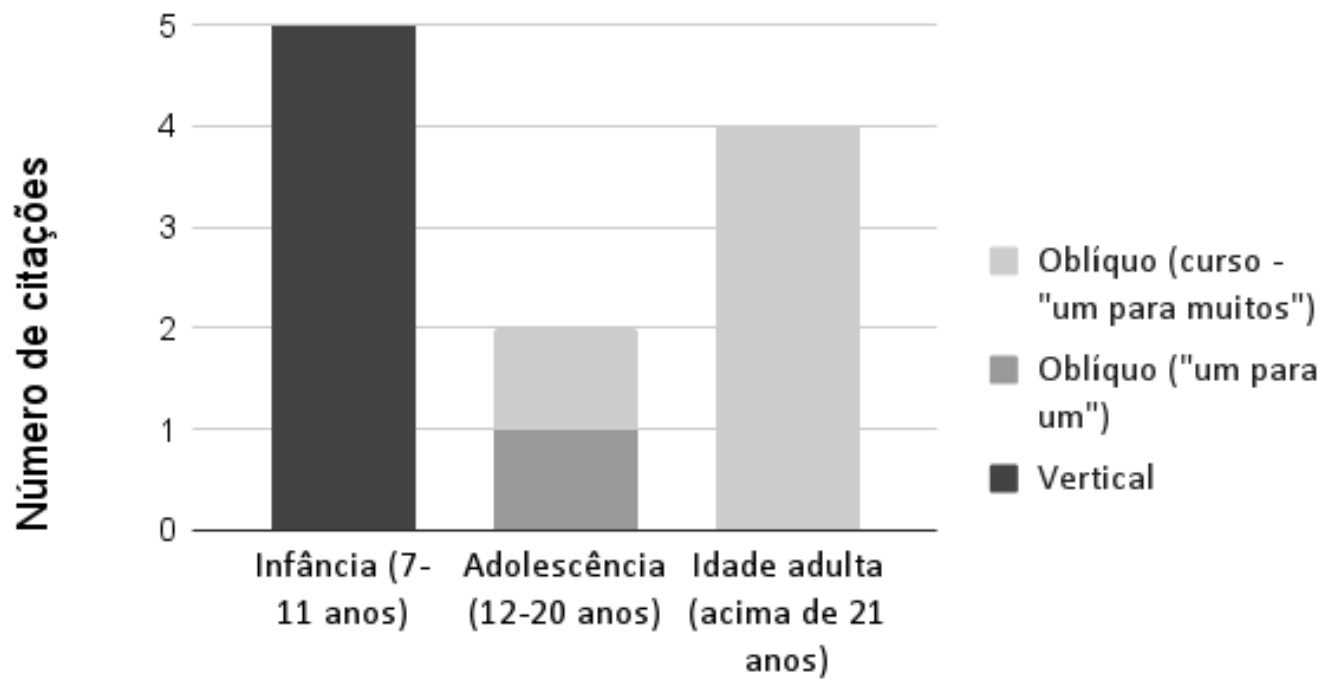

Idade de aprendizagem

Figura 1. Transmissão cultural do conhecimento sobre as benzeduras pelas benzedeiras do leste da ilha de Florianópolis/SC.

Quando questionadas sobre a troca de conhecimento sobre rezas e plantas com outras benzedeiras, as de tradição afirmaram que não costumam realizá-las, pois não possuem muito contato com outras benzedeiras. Já as benzedeiras de religião afirmaram que isso é comum entre elas e todas citaram fazer parte de um grupo virtual fechado em um aplicativo de celular, no qual realizam trocas de informações sobre rezas e plantas com outras benzedeiras. Quando uma benzedeira tem uma pergunta e precisa de mais informações sobre uma oração ou sobre os usos medicinais das plantas, elas colocam no grupo e aqueles que sabem respondem à pergunta. Essas informações não foram investigadas em profundidade, pois não eram o foco inicial desta pesquisa, mas demonstram como as tecnologias têm permitido a troca de informações sem a necessidade de encontros presenciais entre as benzedeiras da região de estudo.

\section{Discussão}

A benzedura na região leste de Florianópolis é realizada majoritariamente por mulheres mais velhas, destacando a importância que as mulheres possuem nesta prática de cura, como já observado em outros estudos (Boing \& Stancik 2013, Geleski 2014, Maciel \& Neto 2006, Moura 2001, Oliveira 1985, Oliveira \& Trovão 2009, SiudaAmbroziak 2018, Sousa et al. 2021, Zank \& Hanazaki 2012). O vínculo desta prática com as mulheres, pode ser resultado de uma divisão histórica de trabalho, na qual os homens normalmente trabalhavam fora de casa e as mulheres eram mais dedicadas às atividades de cuidado da casa e da família, levando-as a ter maior contato com as práticas de atenção à saúde e à espiritualidade (Gill 2010).

Neste estudo, foi constatado que a benzedura é utilizada para tratar uma grande diversidade de problemas de saúde (34), sendo que apenas 8 são realizadas por mais de 2 benzedeiras. O número de problemas de saúde levantados é muito superior ao que foi registrado por Zank e Hanazaki (2016) e Maciel e Neto (2006). O primeiro estudo registrou 20 problemas de saúde tratados por meio de benzeduras através de entrevistas com 41 rezadores da Chapada do Araripe (CE), e o segundo registrou 16 problemas de saúde através de entrevistas com 4 benzedeiras no município de Jurema (MT). Esse elevado número de doenças reflete a importância que essa prática desempenha na atenção básica à saúde das comunidades estudadas, mesmo em uma região urbanizada, com fácil acesso à medicina moderna. Além disso, doenças de causas espirituais ou culturais, como mau olhado, quebrante e embruxado, não são tratadas pela medicina moderna e, portanto, benzeduras e medicina moderna geralmente atuam de forma complementar (Zank \& Hanazaki 2016, Zank \& Hanazaki 2017) 
Cabe destacar a existência de um tipo de doença que parece ser específico da llha de Santa Catarina, o "embruxado" que está associado à cultura antiga e local associada às bruxas da llha. Existem muitas histórias sobre as bruxas e benzedeiras, que fazem parte do imaginário local associado à colonização açoriana (Maluf 1992). Esta reza é realizada por apenas uma benzedeira de tradição e talvez deixe de ser praticada, já que a figura das bruxas na llha vem se modificando com a modernização. Além disso, grande parte das doenças tratadas por benzeduras são realizadas por apenas uma pessoa, o que traz o risco dessas rezas desaparecerem em caso de morte ou mudança de residência destas benzedeiras (Zank \& Hanazaki 2016). Nesse contexto, seria importante incentivar a troca de informações e orações entre as benzedeiras atuais, o que já está acontecendo na área de estudo entre as benzedeiras de religião.

Em relação às plantas utilizadas, assim como em outros estudos, algumas são priorizadas para a realização das rezas, neste caso, $R$. graveolens, $R$. officinalis, $P$. alliacea. Estas mesmas plantas foram destacadas também em estudos com benzedeiras (Maciel e Neto 2006, Zank \& Hanazaki 2016, Oliveira et al. 2018, Clarindo et al. 2019). Estas plantas também são comuns em estudos etnobotânicos em religiões de matriz africana e com outros grupos afro-brasileiros (Pagnocca et al. 2020), demonstrando a importância biocultural dessas plantas no âmbito das práticas religiosas e de cura. $R$. graveolens e $R$. officinalis são plantas de origem mediterrânea, comumente utilizadas no Brasil de forma ritualística contra o mau olhado e para proteção (Pagnocca et al. 2020), e também são utilizadas por suas propriedades medicinais (Lorenzi \& Matos 2008). P. alliaceae é uma planta de origem sulamericana, também usada de forma medicinal e ritualística, mas em altas doses é considerada tóxica e deve ser usada com cautela quando ingerida (Lorenzi \& Matos 2008), o que não é uma preocupação em benzeduras, pois é usado apenas externamente.

Mas para além da reza também existe a indicação de plantas enquanto chá, banho e outros usos, o que indica que o tratamento vai além de questões espirituais e também está diretamente relacionado com aspectos físicos do corpo. Isto está alinhado com a perspectiva holística das práticas tradicionais de saúde, que envolvem diversos aspectos, como o físico, espiritual, emocional, entre outros (Zank \& Hanazaki 2017).

A utilização de ervas em banhos está muito relacionada à percepção de que elas possuem o poder de "descarregar" o corpo e realizar limpeza espiritual (Pagnocca et al. 2020, Van Andel et al. 2013). Segundo as benzedeiras, o corpo "carregado" pode ser causado por "quebrante" (inveja, olho gordo) ou por ataques espirituais de bruxas ou espíritos. Os banhos também são indicados para alguns problemas físicos do corpo, como amarelão, contusão/torção, inflamação, resfriados e erisipela. Os chás são utilizados enquanto um tratamento complementar à reza, para ser realizado em casa pelos atendentes, e estão relacionados principalmente a problemas físicos do corpo.

Sobre as plantas medicinais utilizadas, foi possível observar que ambos os grupos de benzedeiras conhecem e usam plantas no processo de cura. As benzedeiras possuem papel um importante na manutenção e na transmissão dos conhecimentos sobre as plantas medicinais, pois além de cultivarem em suas casas, são pessoas que possuem vastos conhecimentos sobre suas formas de utilização e estão disponíveis a ensinar tanto para os pacientes como para outras benzedeiras.

Em relação a forma de aprendizado e transmissão destes saberes, a transmissão vertical se mostrou predominante na infância, o que também foi observado por outros pesquisadores (Cavalli-Sforza et al. 1982, Reyes-Garcia et al. 2016). Isso possivelmente ocorre, pelo fato das crianças passarem mais tempo com seus familiares, observando e aprendendo através da prática cotidiana (Cavalli-Sforza et al. 1982, Reyes-Garcia et al. 2016). Por outro lado, as dinâmicas atuais das famílias nos centros urbanos vêm mudando essa realidade, já que na atualidade muitas crianças e jovens ficam tempo integral em creches e escolas e com isso possuem um tempo menor de convívio com os familiares, o que pode inclusive influenciar o desinteresse pelas práticas dos mais velhos.

Além disso, também foi observado um predomínio da transmissão oblíqua, que neste estudo está relacionado principalmente ao surgimento de cursos de benzeduras. Isso demonstra que a transmissão oblíqua é importante na formação de conhecimento nos adultos, como verificado por Reyes-Garcia (2016), porque fornece oportunidades de inserção de novos conhecimentos que podem ser adaptados levando a mudanças culturais ao longo das gerações, também citado em outros trabalhos (Cavalli-Sforza et al. 1982, Reyes-Garcia et al. 2016, Zank \& Hanazaki 2012). A transmissão oblíqua contribui para a troca de informações que podem complementar o conhecimento prévio que tinham ou até mesmo substituí-lo (Reyes-Garcia et al. 2016, Santoro et al., 2020). 
A respeito da opinião das benzedeiras em relação aos cursos que vêm sendo ministrados, as de religião disseram achar importante que eles aconteçam como uma forma de dar continuidade a esta prática. Elas também acreditam que é importante que haja o reconhecimento e oficialização dos cursos, pois assim estes poderão servir como ferramenta política para legitimar o ato de benzer. Já as benzedeiras de tradição relataram não saber sobre a existência de cursos de benzeduras e ao serem questionadas sobre o que acham desta forma de aprendizagem, todas consideraram importante a existência desses cursos, pois podem contribuir para a continuidade da prática.

Os resultados demonstram que a prática da benzedura continua exercendo um papel importante na região leste de Florianópolis. Associado a isso, também registramos a inserção de tecnologias no processo de transmissão desses conhecimentos, o que pode estar refletindo um processo de adaptação necessário à manutenção desta prática nos tempos atuais. Acreditamos que a conexão entre tradição e modernidade pode beneficiar a saúde das comunidades, mas é importante investigar as possíveis implicações para a resiliência ou vulnerabilidade desses sistemas de saúde. Além do mais, destacamos a importância de fomentar a organização social das benzedeiras do município de Florianópolis, para que assim seja possível fortalecer esta prática e garantir o reconhecimento e o direito de realizarem as benzeduras em espaços formais de saúde, como já ocorre em alguns municípios brasileiros (Almeida 2012).

\section{Limitações do estudo}

Esta pesquisa foi realizada como trabalho de conclusão de curso de graduação e sem recursos financeiros, não sendo possível estender a investigação para outras regiões da llha de Santa Catarina. Além disso, não nos propusemos a investigar inovaç̃̃es tecnológicas na transmissão cultural com este estudo. Essa foi uma informação nova que surgiu durante a realização da pesquisa e optamos por abordá-la nos resultados, a fim de estimular novos estudos sobre $o$ assunto.

\section{Conclusões}

A prática da benzedura desempenha um papel importante na atenção à saúde das comunidades investigadas, mesmo frente ao processo de urbanização e modernização. Foram levantados diversos problemas de saúde e males tratados pelas benzeduras, sendo que algumas rezas são compartilhadas por mais de uma benzedeira. Em relação à utilização de plantas medicinais é notável a importância que essas plantas têm nesta prática, tanto para utilização nas rezas como para indicações de chás e banhos. Por mais que a transmissão vertical tenha se destacado neste estudo, a transmissão oblíqua também desempenha um papel importante na idade adulta, principalmente associada a cursos. Os dados levantados neste estudo demonstram a conexão entre tradição e modernidade, já que as práticas tradicionais continuam mantendo sua função e estão passando por inovações, como um processo de adaptação frente à modernização com os cursos e os aplicativos de celulares para a troca de informações. Desta forma, recomendamos que estudos futuros sejam realizados de forma a compreender a influência das tecnologias nas práticas tradicionais de saúde.

\section{Declarações}

Lista de abreviações: SC - Santa Catarina; MT - Estado de Mato Grosso

Aprovação ética e consentimento para participar: $O$ desenvolvimento do estudo seguiu as orientações éticas e legais para o desenvolvimento da pesquisa sobre conhecimento tradicional. O projeto foi aprovado pelo Comitê de Ética em Pesquisa com Seres Humanos da Universidade Federal de Santa Catarina (CEPSH) através do número: 82427718.0.0000.0121 de 18/06/2018 e a participação dos colaboradores esteve condicionada a aceitação do Termo de Consentimento Livre e Esclarecido. O projeto foi cadastrado no SISGEN sob o número A011D4A.

Consentimento para publicação: Não aplicável Disponibilidade de dados e materiais: Não aplicável Interesses competitivos: Não aplicável

Financiamento: Não aplicável

Contribuição dos autores: C.F.S. coletou os dados, analisou e redigiu o texto. S.Z. participou da fundamentação teórica, acompanhou a coleta e análise dos dados, auxiliou nas discussões e redigiu a versão final do texto.

\section{Agradecimentos}

Agradecemos a todas e todos os benzedeiros que contribuíram com esta pesquisa, compartilhando seus conhecimentos. Gostaríamos de homenagear o Rodrigo Castro Ramires, único benzedor do sexo masculino, que compartilhou informações detalhadas sobre a dinâmica das benzeduras dentro da religião de matriz africana e faleceu alguns meses após a realização da pesquisa de campo. 


\section{Literatura citada}

Almeida AWB. 2012. Conhecimentos Tradicionais e mobilizações políticas: o direito de afirmação da identidade de benzedeiras e benzedores, municípios de Rebouças e São João do Triunfo, Paraná-Manaus. Editora da Universidade do Estado do Amazonas, Brasil.

Amorozo MC. 1999. Medicina Tradicional em Santo Antônio do Leverger-MT: a permanência de práticas antigas e o papel dos benzedores e suas habilidades. Revista Saúde e Ambiente 2:48-66.

Ávila JVC. 2012. Etnobotânica de plantas utilizadas como medicinais pelos benzedores nos municípios de Imbituba e Garopaba-SC-Brasil. Monography, Federal University of Santa Catarina.

Bernard HR. 2005. Research methods in anthropology: qualitative and quantitative approaches. AltaMira Press, Lanham, USA.

Boing L, Stancik MA. 2013. Benzedeiras e benzimentos: práticas e representações no município de Ivaiporã-ParanáBrasil. Ateliê de História 1:85-96.

Brasil. 1990. Lei n. 8.069, Estatuto da Criança e do Adolescente. http://www.planalto.gov.br/ccivil_03/Leis/L8069.htm (Accessed 08/11/2021).

Cavalli-Sforza LL, Feldman MW, Chen KH, Dornbuscch SM. 1982. Theory and observation in cultural transmission. Science 218 (1):19-27

Clarindo MF, Strachulski J, Floriani N. 2019. Curandeiros Parintintin e benzedeiras: reprodução do saber popular de cura. Hygeia - Revista Brasileira de Geografia Médica e da Saúde 15 (31):105-124

Cunningham AB. 2001. People, wild plant use and Conservation. Applied Ethnobotany, London, U.K.

Dias LG. 2009. "O que é que eu côso?":uma etnografia sobre benzedeiras e benzeduras da Lagoa da Conceição, Florianópolis, Santa Catarina-Brasil. Monography, Federal University of Santa Catarina.

Dias LG. 2013. O poder na e da voz delas: benzedeiras da Itha de Florianópolis, Santa Catarina-Brasil.Master 's thesis, Federal University of Santa Catarina.

Fonseca-Kruel VS, Peixoto AL. 2004. Etnobotânica Reserva Extrativista Marinha de Arraial do Cabo, Rio de JaneiroBrasil. Acta Botanica Brasilica 18: 177-190

Geleski FS. 2014. Benzedeiras na Ilha de Santa Catarina a partir da perspectiva de Oswaldo Rodrigues Cabral. Revista Santa Catarina em História 8 (1): 150-162.

Gill LA. 2010. Benzedeiros Em Pelotas (RS): entre o dom, a tradição e a religião. Anais X Encontro Estadual de História, Federal University of Pelotas.

Hoffmann-Horochovski MT. 2012. Velhas Benzedeiras. Revista de Ciências Sociais 17(2): 126-140.

IBGE, Instituto Brasileiro de Geografia e Estatística. 2010. Infográficos: dados gerais do município de Florianópolis, Santa Catarina -Brasil. https://cidades.ibge.gov.br/painel/painel.php?codmun=420540(Accessed 24/06/2021)

Klein RM. 1978. Flora ilustrada catarinense: mapa fitogeográfico do Estado de Santa Catarina. Herbário Barbosa Rodrigues, V Parte - mapa fitogeográfico, Itajaí, Brazil.

Lorenzi H, Matos FJA. 2008. Plantas Medicinais no Brasil: nativas e exóticas. Instituto Plantarum, Nova Odessa, Brazil. Lozada M, Ladio A, Weigandt, M. 2006. Cultural transmission of ethnobotanical knowledge in a rural community of northwestern Patagonia, Argentina. Economic Botany 60: 374-378.

Maciel MRA, Guarim Neto G. 2006. Um olhar sobre as benzedeiras de Juruena (Mato Grosso, Brasil) e as plantas usadas para benzer e curar. Boletim do Museu Paraense Emílio Goeldi 1: 61-77.

Magalhães SM. 2004. Alimentação, saúde e doenças em Goiás no século XIX. Doctoral Thesis, Universidade Estadual Paulista Júlio de Mesquita Filho.

Maluf SW. 1992. Bruxas e bruxarias na Lagoa da Conceição: um estudo sobre representações de poder feminino na Itha de Santa Catarina. Revista crítica de Ciências Sociais 34: 99-112.

Moura ECD. 2001. Eu te benzo, eu te livro, te curo: nas teias do ritual de benzeção. Revista de Humanidades 29 (11): 340- 369.

Oliveira ER. 1985. O que é benzeção. Editora brasiliense, São Paulo, Brazil.

Oliveira ECS, Trovão, DMBM. 2009. O uso de plantas rituais de rezas e benzeduras: um olhar sobre esta prática no estado da Paraíba. Revista Brasileira de Biociências 7 (3): 245-251.

Oliveira EP, Taques EM, Moreira PVS, Sieben CR, Lorenzetti ER. 2016. Plantas medicinais empregadas em desenvolvimento na Região de Palmas, Paraná-Brasil. Cadernos de Agroecologia 11 (2). 
Pagnocca TS, Zank S, Hanazaki N. 2020. "The plants have axé": investigating the use of plants in Afro-Brazilian religions of Santa Catarina Island. Journal of Ethnobiology and Ethnomedicine 16(20):1-13.

Reyes-García V, Gallois S, Demps KA. 2016. Multistage learning model for cultural transmission: evidence from three indigenous societies. In: Terashima H., Hewlett B. (eds) Social Learning and Innovation in Contemporary HunterGatherers. Replacement of Neanderthals by Modern Humans Series. Springer, Tokyo.

Santoro FR, Chaves LS, Albuquerque UP. 2020. Evolutionary aspects that guide the cultural transmission pathways in a local medical system in Northeast Brazil. Heliyon 6. e04109 https://doi.org/10.1016/j.heliyon.2020.e04109

Silva MAS. 2016. Cultura Açoriana no contexto da cidade-mercadoria: da invisibilidade à mercantilização Florianópolis/SC. Caminhos de Geografia 17: 144-161.

Siuda-Ambroziak R. 2018. Benzedeiras em vias de extinção na Ilha da Magia. Métis: História \& Cultura 34 (17) : 125146.

Soares MS. 2001. Médicos e mezinheiros na corte imperial: uma herança colonial. História, Ciências, Saúde 8 (2): 407 - 38

Sousa MC, Queiroz GS, Morais MGG, Albuquerque LTC, Malheiro DR, Oliveira CDM. 2021. Cura pela fé: as benzedeiras do Cariri Cearense/Healing by faith: the benzedeiras de Cariri Cearense. Revista Multidisciplinar e de Psicologia 15 (54): 323-332.

Van-Andel TR, Ruysschaert S, Putte KV. 2013. What makes a plant magic? Symbolism and sacred herbs in afrosurinamese rituals. In African Ethnobotany in the Americas. Edited by R Voeks, J Rashford. Springer, New York, Pp. 247-284.

Zank S, Hanazaki N. 2012. Exploring the links between ethnobotany, local therapeutic practices, and protected areas in Santa Catarina coastline - Brazil. Evidence-based Complementary and Alternative Medicine 1-15.

Zank S, Hanazaki N. 2016. Healing faith: knowledge, learning and social relationships of healers from Araripe plateau - Brazil. Ethnobiology and Conservation 5: 1-15.

Zank S, Hanazaki N. 2017. The coexistence of traditional medicine and biomedicine: A study with local health experts in two Brazilian regions. PloS one 12(4): 1-17. 